\title{
Ideias de ativismo regional: a transformação das leituras brasileiras da região
}

\author{
Ideas of regional activism: the transformation of Brazilian \\ readings of its region
}

MATIAS SPEKTOR *

Rev. Bras. Polít. Int. 53 (1): 25-44 [2010]

\section{Introdução}

Ao longo dos últimos trinta anos, a transformação das atitudes brasileiras em relação à vizinhança têm sido dramáticas. Até o ano de 1981, por exemplo, nenhum chefe de Estado brasileiro havia visitado o Peru ou a Colômbia. Em que pesem as diferenças de estilo e prioridades dos sucessivos governos do Brasil, a inovação em assuntos regionais é inquestionável. Uma explicação satisfatória para esse fenômeno deve levar em conta as causas estruturais, institucionais e conceituais que moldam a trajetória da política regional do Brasil.

Sem ignorar os fatores causais apontados acima, este artigo analisa o papel das idéias na conformação do renovado ativismo regional brasileiro com ênfase para a última década. O objetivo é identificar as crenças e conceitos estratégicos básicos que circulam no mercado de ideias diplomáticas em Brasília e ajudam a explicar os porquês do perfil crescentemente assertivo do Brasil em seus negócios regionais.

A literatura especializada sobre o papel das idéias nas relações internacionais é vasta e influente. Trabalhos recentes têm privilegiado o lugar das ideias no sistema internacional (Tannenwald e Wohlforth, 2005; Risse-Kappen, 1994); o impacto de ideias em ambientes regionais e regimes internacionais (Acharya 2004, Acharya 1997, Keck e Sikkink, 1998; Finnemore, 2003; Foot, 2000); e o papel das ideias nas escolhas estratégicas das grandes potências (Goldstein, 1993; Rose, 1998; Foot, 2001). Este artigo utiliza instrumentalmente essa literatura para indagar sobre as escolhas regionais do Brasil. Especificamente, o artigo cumpre três funçõos principais: a) caracteriza o padrão brasileiro de ativismo regional; b) apresenta os conceitos estratégicos básicos que têm informado o

* Professor da Fundação Getúlio Vargas do Rio de Janeiro-FGV-RJ (Matias.spektor@gmail.com). 
comportamento brasileiro na região e; c) aponta eventuais contradições e silêncios embutidos nessas ideias. ${ }^{1}$

\section{O ativismo brasileiro na região}

Esta seção busca caracterizar o padrão de ativismo brasileiro na vizinhança. Desde meados da década de 1980, a diplomacia brasileira moveu-se decididamente em direção à região (Burges, 2008; Flemes, 2006; Lima e Hirst, 2006). A região passou a ocupar espaço inédito na agenda diplomática brasileira, e Brasília vem reagindo a eventos regionais, positivos ou negativos, com políticas que refletem uma intenção de manter, recompor ou promover a cooperação e a aproximação. Mesmo diante de enormes problemas e alguns fracassos, a atitude dominante no Brasil tem sido a de apostar no regionalismo. Sucessivos governos desde a década de 1980 vêm expandindo consistentemente suas agendas regionais. Não há dúvidas de que o Brasil é hoje um dos principais entusiastas da proliferação de iniciativas regionais que marcam a América do Sul.

Entretanto, apesar do claro alargamento dos compromissos regionais brasileiros, qualquer análise sobre a política regional do Brasil ainda deve levar em conta a enraizada ambivalência do país em relação à vizinhança (Hurrell, 1992). Mesmo após anos de crescimento econômico estável e de uma política externa em ampliação, o Brasil não é uma potência regional típica. Por um lado, seus recursos materiais sugerem ser esta uma clara potência regional. Afinal de contas, o Brasil responde, sozinho, por mais da metade do território, população e riqueza da América do Sul; sua capacidade militar, apesar de ter limitações reais, supera em muito a de seus vizinhos. Além disso, o Brasil ancorou seu poder em uma rede de laços formais com a regiáo e se transformou no principal patrocinador de novas instituições.

Por outro lado, contudo, não há indicações inequívocas de que o Brasil se comporte como potência regional. O país não assume a posição de principal agente da ordem regional e hesita diante de situaçôes onde é forçado a se impor. Sucessivos governos brasileiros têm sido relutantes diante da ideia de custear a proeminência regional do país, especialmente quando isto significa pressionar vizinhos menores a respeitar o número crescente de regras formais que estrutura a vizinhança. O Brasil

1 Este artigo é um esforço interpretativo inspirado em ricas fontes primárias, mas não é um trabalho de história internacional, porque os documentos que o inspiraram ainda estão fechados para a consulta pública. As fontes em questão são produto de longas entrevistas de História Oral com mais de dez personagens de política externa conduzidas no âmbito do projeto "Relações internacionais e política externa do Brasil desde o fim da Guerra Fria”, do Centro de Pesquisa sobre História Contemporânea do Brasil da Fundação Getulio Vargas (CPDOC/FGV). Fiz uso, igualmente, de informações de uma coleção de arquivos pessoais pertencentes a renomados diplomatas que foram depositados no CPDOC nos últimos anos. No momento de redação deste artigo esses acervos estão sendo organizados, catalogados e digitalizados, e estarão disponíveis para a pesquisa no futuro próximo. Minha intenção ao publicar este artigo antes da liberação da documentação relevante é contribuir para a produção do maior número possível de observações e proposições preliminares ao detalhado trabalho de arquivo. 
também não adota a atitude de algumas potências regionais no sentido de abraçar os princípios da interdependência complexa para promover formas de cooperação em casos nos quais problemas comuns demandam soluções compartilhadas, que podem ir da vacinação de gado ao controle do tráfico de armas na fronteira. Assim, o Brasil não relativizou noções tradicionais de autonomia nacional e continua tendo baixa expectativa em relação ao compromisso dos vizinhos com os interesses brasileiros. Apesar de o Brasil incentivar a institucionalização das relações regionais, a arquitetura resultante continua sendo minimalista e relativamente fraca - em boa parte porque essa é a preferência brasileira.

Em que pesem essas importantes ressalvas, a evidência é clara: o Brasil vem perseguindo uma política regional crescentemente ativista. Basta comparar a década de 1980, marcada pelas as tentativas iniciais de reconciliação com a Argentina e pelos ensaios de aproximação regional do Grupo do Rio, com o complexo quadro de iniciativa regionais dos anos 1990. Um indicador útil aqui é o número de viagens presidenciais pela América do Sul: antes raras, hoje as reuniões de trabalho, cúpulas oficiais e encontros informais com vizinhos ocupam a maior parte do tempo presidencial dedicado à política externa. Em seu discurso inaugural, em 2003, o chanceler Celso Amorim descreveu a política regional como brasileira como um "ativismo responsável" - responsável ou não, o modo operacional tem sido, sem dúvida alguma, ativista. ${ }^{2}$

A ambiguidade do ativismo regional está calcada no padrão de institucionalização que o Brasil vem promovendo. Na década de 1990, por exemplo, o país patrocinou um bloco comercial cujo objetivo de longo prazo era aumentar a integração política e social da região - o Mercosul. Coube ao Brasil a responsabilidade por advogar, inicialmente, a abertura do Mercosul a novos membros e expandir seu desenho original. Apesar da resistência brasileira a quaisquer formas de supranacionalidade, o grupo hoje conta com uma secretaria geral, um tribunal e um fórum parlamentar. Seu secretariado técnico emite um número crescente de normas e regulamentações relativamente intrusivas. No ano 2000, foi do Brasil a ideia de promover a primeira cúpula de chefes de Estado da América do Sul, assim como a fusão entre o Mercosul e a Comunidade das Naçōes Andinas para a criação de uma Comunidade das Nações Sul-Americanas. Ainda nessa direção, o Brasil também concordou em responder às demandas dos vizinhos menores por um banco de desenvolvimento regional, embora o fizesse de maneira relutante e parcial.

O ativismo também pode ser visto no uso instrumental que o Brasil vem fazendo do regionalismo sul-americano em negociaçôes globais com atores extraregionais. No caso de negociações comerciais, o Brasil muitas vezes opera para ser reconhecido como um país que não fala apenas por si mesmo, mas como interlocutor relevante que pode falar pelo grupo dos países da região. A noção de

2 Celso Amorim, 1 de janeiro de 2003. 
regionalismo aparece também no centro da estratégia brasileira para lidar com questôes relativas a normas internacionais de democracia e direitos humanos, proliferação nuclear, segurança internacional e migração. Finalmente, e apesar da oposição de alguns países regionais, a América do Sul tem figurado uma e outra vez, embora de forma geralmente tácita, na argumentação brasileira sobre a necessidade de uma reforma do Conselho de Segurança da ONU que conceda ao Brasil um assento permanente (Vargas, 2008).

Um indicador adicional da guinada em direção à região é o fato de o Brasil responder a crises regionais com mais - não menos - engajamento. Por exemplo, diante da tentativa de golpe no Paraguai em 1997, o Brasil sinalizou aos conspiradores que jogaria todo seu peso contra eles e, também por causa disso, o golpe não aconteceu. Entre 1995 e 1998, o Brasil esteve no centro da mediação da disputa territorial entre Equador e Peru e, em 2002, assumiu um posicionamento ativo de estabilização da Venezuela após a tentativa falida de golpe contra Hugo Chávez. Na década de 2000, pela primeira vez o governo brasileiro manifestou real interesse no conflito colombiano e alguns membros do governo assinalaram que o Brasil deveria desempenhar um papel político em sua resolução. No âmbito latinoamericano, quando o Conselho de Segurança da ONU designou uma operação para o Haiti, o Brasil ofereceu-se para lidara-la e arcar com a maior parte dos custos e homens. Finalmente, em 2008, quando tropas colombianas perseguiram e assassinaram membros das FARC em território equatoriano, a resposta brasileira foi pouco usual: indo contra uma arraigada tradição nacional de rejeição a quaisquer formas de institucionalização da segurança regional, advogou ideias de segurança coletiva sob a forma de um Conselho Sul-Americano de Defesa.

A evidência existente também sugere que, ao menos desde a segunda metade da década de 1990, o país adotou posiçōes mais intrusivas em questōes regionais. Ao menos em assuntos relacionados à democracia e às regras democráticas, a opção foi por não adotar uma política baseada estritamente em princípios de soberania e não-ingerência. Contrariamente a essa abordagem tradicional, a nova ênfase recai sobre a ideia de que o interesse brasileiro na região passa, em parte, por um conjunto de princípios básicos sobre a governança no interior dos países vizinhos. Foi essa a tônica do governo Fernando Henrique Cardoso no caso paraguaio. Da mesma forma, em seu discurso de posse, o presidente Lula notou que "muitos de nossos vizinhos hoje vivem situações difíceis", e assinalou que o Brasil estaria disposto a tomar partido ao fazer uma "contribuição". Em 2004, esses argumentos encontraram expressão doutrinal pela primeira vez em discurso proferido na China: "A crescente aproximação e consolidação das relações do Brasil com sua região requerem que a situação de instabilidade nesses países mereça um acompanhamento mais atento por parte do governo brasileiro, que é orientado pelo princípio da não-intervenção, mas também pela atitude da 'não-indiferença."’3

3 Presidente Lula, Universidade de Pequim, 25 de maio de 2004. 
Lula reforçou o ponto na Assembléia Geral da ONU, no mesmo ano, dizendo que "nós não acreditamos em interferência externa em questões internas, mas não procuramos refúgio na omissão e indiferença perante os problemas que afetam nossos vizinhos." ${ }^{\text {‘ }}$

Essas transformaçóes, embora limitadas e possivelmente reversíveis, revelam o escopo da transformação da atitude brasileira em relação à região. Há, entretanto, tensões recorrentes, conforme apontado acima. O movimento em direção à região convive com uma política externa que enfatiza soluções nacionais mesmo quando os problemas são compartilhados, busca o desenvolvimento econômico interno, mantém firmes suspeitas sobre as intenções dos vizinhos, é cautelosa e avessa ao risco. Na vizinhança, a percepção dominante em relação ao Brasil é a de que o país, apesar de ser o principal centro de poder regional, não traduz essa ascendência em liderança amigável. Segundo essa visão, não é fácil seguir o Brasil a reboque. Mesmo que os vizinhos não temam uma suposta dominação brasileira nem tenham uma visão negativa das intençõos do Brasil, eles sentem que o país não responde eficazmente à vasta assimetria de poder que marca a região. Paraguai, Uruguai, Bolívia e Argentina sentem-se comumente negligenciados pelo Brasil. Assim, apesar do peso relativo do Brasil, nas praças diplomáticas sul-americanas, não é óbvio que Brasília seja capaz ou tenha interesse em catalisar o ordenamento regional. Se uma potência regional precisa de seguidores para ser vista como tal pelo resto do mundo, então as credenciais brasileiras nesse quesito são dúbias.

Essa ambivalência reflete as prioridades das elites do Brasil. Pesquisas recentes revelam o grau em que elas vêem a América do Sul como uma fonte de "problemas e preocupaçōes”. Em parte, esses dados devem ser lidos como uma reação brasileira ao avanço do populismo e formas autocráticas de governo em alguns dos países sulamericanos. Também são resultados da noção de que a extensa fronteira amazônica e o tráfico de drogas produzidas em países vizinhos constituem a principal fonte de insegurança do país. E, finalmente, resultam da ideia comum, no Brasil, de que o principal obstáculo ao avanço do Mercosul reside no protecionismo dos vizinhos (mas não do Brasil). Não surpreende, portanto, que as elites brasileiras prefiram avançar em negociações comerciais no âmbito da $\mathrm{OMC}$ e em negociações bilaterais com o mundo industrializado antes de aprofundar a integração sul-americana. Ao longo da década de 2000, por exemplo, houve uma queda significativa do apoio desse grupo da população ao Mercosul (Souza, 2008).

A opinião pública brasileira de modo mais amplo não apresenta visões muito diferentes. Como aprenderam os presidentes Fernando Henrique Cardoso e Luiz Inácio Lula da Silva, o ativismo em política externa muito rapidamente traz à tona reações cautelosas e avessas ao risco. A tônica é dada pela visão segundo a qual o país ainda sofre de grandes mazelas internas para aventurar-se de modo ativo

4 Para o discurso inaugural, Presidente Lula, 1 de janeiro de 2003; Presidente Lula, LIX UNGA, Nova York, 21 de setembro de 2004. 
pelas relações internacionais. No mercado de ideias nacionais, há pouco espaço para o alargamento das ambiçóes internacionais do país. Mesmo quando essas ideias aparecem em cena, precisam competir contra outras, mais poderosas, que enfatizam a fragilidade interna. Tanto à esquerda quanto à direta do espectro político encontra-se o argumento de que uma política externa assertiva é custosa e arriscada. Seguindo a mesma lógica, grandes temas nacionais - como a violência urbana, a redução da pobreza e a entrada das classes mais baixas no mercado consumidor - quase nunca são vistos como problemas de política externa ou política comercial externa, apesar de sua poderosa conexão internacional.

É curioso notar que os críticos das políticas externas de FHC e Lula, apesar de estarem em muitas ocasiōes em posições opostas, utilizam adjetivos similares que enfatizam a natureza ativista da diplomacia que buscam desqualificar: "hiperativo", "exibicionista" e "pretensioso" aparecem uma e outra vez nas páginas dos principais jornais. O ponto é que o ativismo de um e outro presidentes não foi nem é consensual, e em ambos os casos foi necessário lançar mão de esforço retórico significativo para legitimar políticas externas crescentemente ambiciosas diante de um público hesitante. Se uma potência regional bem-sucedida precisa envolver-se ativamente no espaço regional que habita, então o Brasil tem tido alguns problemas para assegurar apoio doméstico para o projeto regionalista.

Para finalizar esta seção é útil apontar que, ao estudar o ativismo regional do Brasil, vale a pena levar em conta duas preocupações metodológicas. É possível que aquilo que parece ser maior envolvimento na região apenas reflita a proliferação de compromissos brasileiros em todo o mundo. Talvez o Brasil tenha tomado mais iniciativas em sua região porque o escopo de suas ambições internacionais cresceu como um todo em todas as áreas, não em função de uma leitura nacional sobre a utilidade de promover o engajamento regional. Afinal, a trajetória internacional do Brasil tende ao alargamento há mais de trinta anos e ganhou força com a redemocratização. Os presidentes José Sarney, Fernando Collor de Mello, Fernando Henrique Cardoso e Luís Inácio Lula da Silva visitaram mais países e receberam mais visitas oficiais do que qualquer um dos seus predecessores. Ao fim do mandato de FHC, o New York Times reportou que o Brasil havia agora começado a "desempenhar um papel no cenário mundial" - comentário que seria sistematicamente repetido desde o início do governo Lula em 2003.5

Outra precaução metodológica importante diz respeito ao lugar do ativismo regional brasileiro no âmbito do ativismo regional de outros países da região. Quando comparada com as políticas externas de outros países sul-americanos, a proliferação de compromissos regionais da diplomacia brasileira é menos impressionante do que a primeira vista. Afinal, todos os principais países da América do Sul têm se voltado para a região de maneira inédita. Um exemplo é a Argentina: se seu chanceler costumava caracterizar o país como um "europeu na

5 New York Times, 30 de agosto de 2000. 
América Latina" no início da década de 1990, na década de 2000 a ênfase está na proliferação de laço de Buenos Aires com La Paz, Caracas e Brasília. Outro exemplo nítido é a Venezuela, que tem adotado um perfil ativista de altíssima visibilidade na região e cujo objetivo é projetar e desenvolver um ambiente normativo supostamente bolivariano. Mesmo Chile, Peru e Colômbia, países da costa do Pacífico que buscaram associar-se mais proximamente aos Estados Unidos, multiplicaram e participam ativamente de inúmeras iniciativas regionais.

Tendo essas ressalvas em mente, quais ideias têm estruturado o ativismo regional do Brasil?

\section{As motivações regionais do Brasil}

Esta seção tem por foco dois grupos de ideias explanatórias: as sobre limites e fronteiras do que viria a ser a "região do Brasil", e as sobre a natureza do poder brasileiro nas relações internacionais.

\section{As novas fronteiras regionais}

A literatura existente sobre regionalismo mostra que as regiōes do mundo são construçôes sociais contingentes. Assim, os limites geográficos de uma região pouco têm de óbvio ou natural, e suas fronteiras resultam de um embate político que envolve as percepçóes, interesses, valores e identidades de jogadores-chave dentro e fora da região - vide o uso seletivo que tanto China quanto Estados Unidos fazem de conceitos pouco precisos como "Ásia", "Ásia-Pacífico", "Nordeste Asiático" e "Sudeste Asiático". Nesse sentido, as regiôes são claramente "comunidades imaginadas". O ponto básico para esta análise é que a noção de "região" é objeto de contestação política (Fawcett e Hurrell, 1995).

Uma análise da evolução das leituras brasileiras do ambiente regional ilustra a questão vivamente. Desde princípios dos anos 1990, argumentos começaram a circular dentro do Ministério das Relações Exteriores que questionavam a utilidade de definir a região em que o Brasil se insere como "América Latina". Crescentemente, a tônica dominante foi a de desconforto com essa etiqueta. Parte do problema era a interpretação brasileira sobre o papel (deletério) do México sobre os interesses regionais do Brasil: por um lado, aquele país escolhera aproximar-se dos Estados Unidos mais do que Brasília considerava palatável; por outro, em meio ao esforço brasileiro por assegurar algum grau de estabilidade financeira interna, o México representava uma fonte regular de instabilidade que facilmente podia se espalhar para o sul.

$\mathrm{Na}$ visão brasileira o México escolhera adaptar-se ao fim da Guerra Fria pelo abandono de um "projeto nacional próprio", abrindo mão de qualquer expectativa autonomista diante da expansão da interdependência complexa típica da era da globalização. As escolhas mexicanas davam relevo a um medo recorrente da leitura 
brasileira sobre a natureza do sistema internacional: a força da globalização podia, sim, varrer o acervo diplomático autonomista até mesmo de um país que, durante boa parte do século XX, estruturara sua presença no mundo e ganhara projeção mediante algum distanciamento da potência hegemônica. Aos olhos de sucessivas lideranças em Brasília, mesmo uma ideologia enraizada de desenvolvimento e industrialização nacional podia render-se diante da avalanche da sociedade internacional liberal.

O outro problema com o México tinha a ver com sua instabilidade financeira naquele período. Essa percepção veio à tona em Brasília durante a crise financeira asiática que abateu sobre México e Brasil no início do ano de 1998 e que, no caso do último, ameaçou a sobrevivência do plano de estabilização doméstica de 1994 - o Real. Além da óbvia preocupação econômica, a crise financeira do ano de 1998 tinha características estratégicas para Brasília. O Plano Real encerrara uma década de decadência econômica e hiperinflação. Não apenas assegurara a vitória de um novo modelo de política econômica e atraíra um fluxo inédito de investimentos externos, mas também fora instrumentalizado como uma credencial para sinalizar ao mundo que o país agora pertencia ao mainstream da sociedade internacional. Fora-se o tempo em que o Brasil não honrava seus compromissos internacionais ou mantinha uma postura essencialmente reativa diante da expansão das ambiçóes normativas do Ocidente. Para muitos tomadores de decisão em Brasília, a estabilidade financeira, conseguida arduamente depois de sucessivos fracassos, era, em si, um dos principais recursos de poder para fazer frente à globalização. Esta diferença entre as leituras de ambos os países é crucial. Diferentemente do caso mexicano, a estabilidade era almejada menos como sinal de entrada acrítica na globalização do que como escudo para negociar algum grau de controle sobre o processo de liberalização econômica.

Quando a crise estourou, o Brasil negociou um plano de resgate massivo com Wall Street, o Tesouro dos Estados Unidos e o Fundo Monetário Internacional (FMI). A ajuda direta do Presidente Bill Clinton permitiu evitar o colapso financeiro e uma espiral inflacionária reminiscente da experiência pregressa do Brasil. Foi nesse contexto de negociação em Washington e Nova York que diplomatas e ministros responsáveis pelo avanço das conversas começaram a identificar a vinculação brasileira ao México via conceito de "América Latina" como um fardo.

Líderes brasileiros perceberam que, ao negociar os termos do pacote de resgate, eles passavam a maior parte do tempo tentando tranquilizar os credores de que o seu país era um devedor confiável (diferentemente do México). O pertencimento à "América Latina" tornava essa argumentação mais difícil porque a memória dos credores ainda estava maculada pelo desastre financeiro latino-americano da década anterior. Como rótulo, a "América Latina" dificultava as negociaçôes com banqueiros, oficiais do tesouro e lideranças políticas americanas. Foi nesses termos que ganhou força o argumento segundo o qual convinha ao Brasil distanciar-se, 
na medida do possível, da "América Latina". A construção regional alternativa que poderia ocupar-lhe o lugar seria a "América do Sul". Embora fosse inicialmente uma operação de marketing voltada para criar confiança nas difíceis negociações por empréstimos em meio à crise, essa transformação terminaria tendo um significado estratégico definitivo para as leituras brasileiras do sistema internacional.

Ainda no curso da crise financeira de 1998, outro evento, agora envolvendo a Argentina, ajudou a reforçar a ideia de que a "América do Sul" seria a melhor plataforma regional do Brasil. Quando os temores sobre o futuro do Real atingiram o ponto mais alto, as autoridades monetárias em Buenos Aires retiraram apoio às escolhas de Brasília e, indo na direção contrária, começaram a sugerir publicamente que o Brasil adotasse uma política de paridade com o dólar (currency board). $\mathrm{O}$ então ministro argentino da fazenda, Domingo Cavallo, fez declaração nesse sentido perante uma platéia de empresários e financistas no retiro de Davos sem negociá-la previamente com seus colegas na Esplanada dos Ministérios. Do ponto de vista de Brasília, isto constituía uma "traição" não apenas porque revelava a fragilidade fundamental a assolar o Mercosul, mas também porque era o tipo de argumento que reforçava politicamente aquelas vozes dentro de instituiçôes financeiras internacionais que, à época, tentavam estabelecer condiçôes rigorosas em qualquer pacote de ajuda para o Brasil. Com Cavallo transformando-se rapidamente em persona non-grata em círculos brasileiros, ganhava momentum a ideia de que a política regional do país precisava ser revista.

Nesse cenário, ainda mais dois eventos na relação brasileiro-argentina ajudariam a enraizar novas apreciações em Brasília sobre a utilidade e orientação do regionalismo. Durante o mesmo ano de 1998, a Argentina negociara, sigilosamente e sem consulta ao Brasil, o status de aliado extra-regional da Organização do Tratado do Atlântico Norte (OTAN). Além disso, quando o Brasil flutuou sua moeda em resposta à crise financeira, a Argentina barrou a entrada de produtos brasileiros, fragilizando ainda mais a fina malha normativa do Mercosul. À medida que a crise financeira jogava a própria Argentina em recessão econômica intensa e inédita ebulição política, o relacionamento bilateral que estivera no coração da estratégia regionalista do Brasil desde a década de 1980 tornava-se progressivamente tenso e de difícil gerenciamento. $\mathrm{O}$ tom amargo da mídia brasileira refletia fielmente o sentimento dominante dos atores-chave do lado brasileiro.

A evidência existente indica que, já em 1999, circulavam documentos no Palácio do Planalto e no Ministério das Relações Exteriores que apontavam a utilidade estratégica de expandir o Mercosul com o propósito explícito de diluir o poder relativo da Argentina dentro do bloco. Em vez de abandonar o projeto regional, seria mais factível e melhor expandi-lo para incluir novos países em um arranjo cooperativo regional mais amplo. $\mathrm{O}$ objetivo era menos limitar o poder argentino do que aumentar o espaço de manobra brasileiro. Esta nova formação não iria substituir o Mercosul, mas o faria menos proeminente nas mesas de negociação. Esta escolha não é trivial e revela uma atitude pró-ativa e interessada 
em aproximar-se do espaço regional: diante da fragilidade e debilidade regional, o país preferiu não retrair seus interesses, mas alargá-los. Por trás dessa lógica residia o entendimento segundo o qual uma entidade sul-americana mais ou menos frouxa funcionaria como saída legítima para a paralisia em que se encontrava o Mercosul às vésperas da virada de século. Assim, em setembro do ano 2000, o Brasil convidou os chefes de Estado sul-americanos para o que era o primeiro encontro dessa natureza na história da região (o ministro das relações exteriores mexicano recebeu um convite formal depois de trocas afiadas com o Brasil).

O que merece atenção especial neste caso é o fato de a lógica por trás das escolhas brasileiras não ser aquela segundo a qual uma entidade sul-americana era útil e necessária para resolver problemas de ação coletiva, promover a coordenação regional ou gerenciar problemas comuns típicos da interdependência complexa entre fronteiras porosas na região. Ao contrário, a lógica que animava Brasília era a de utilizar um novo arranjo regional como ferramenta para resgatar espaço de manobra diante da crise financeira e de um Mercosul moribundo e decadente. Assim, a origem da ideia de "América do Sul" teve menos a ver com novas ideias sobre governança coletiva ou sobre uma suposta identidade regional comum do que com um cálculo instrumental calcado em consideraçôes de poder e autonomia.

Dessa maneira, o impacto estratégico da crise financeira de 1998 foi o de levar o Brasil a reavaliar os contornos de sua região. Ganhou força a ideia de que as fronteiras imaginárias do espaço regional precisariam ser adaptadas se o Brasil fosse ser bem-sucedido em um ambiente internacional crescentemente desafiador.

\section{A natureza do poder brasileiro}

Um dos aspectos mais peculiares das ideias brasileiras sobre o poder nacional no século vinte é a relativa escassez de referências à região como um importante componente desse poder. Um exemplo são as demandas brasileiras por status especial na sociedade internacional - seja nas Conferências de Haia, na Liga das Naçōes, na Conferência de São Francisco ou em Bretton Woods. Em todas essas instâncias o Brasil demandou status diferenciado fundando seus argumentos no acervo acumulado de sua tradição diplomática, em seu papel construtivo na resolução de conflitos, na aderência a instituições multilaterais, em seu tamanho e seu interesse mais geral de contribuir para a harmonia internacional. Quando a região aparece na argumentação, o faz apenas de forma tangencial e indireta.

O que não aparece nessa lista de justificativas é a noção de que parte do pleito resulta do fato de o Brasil ser o maior, mais rico e mais populoso país de sua região imediata e que, portanto, ora a representa, ora ajuda a gerenciá-la. A busca brasileira por um assento permanente em um Conselho de Segurança da ONU reformado - reintroduzida, depois de muitos anos, na década de 1990 e intensificada na de 2000 - segue um padrão similar: o país guarda relativo silêncio sobre o papel da região nesse pleito (em parte porque México e Argentina têm 
buscado minar quaisquer argumentos de "representação regional" que o Brasil tente avançar). Assim, o argumento de que o Brasil é um candidato a ter status especial porque representa sua região ou está disposto e é capaz de coordenar a ordem naquela parte do mundo nunca chegou a ser articulado plenamente por Brasília - aparece geralmente nas entrelinhas, de forma implícita e muitas vezes tortuosa. A curiosa premissa não falada sugere que um país pode ser relativamente poderoso e influente sem ter de necessariamente ser uma "potência regional" na região em que se insere. Isto é precisamente o que se vê, por exemplo, na primeira tentativa explícita de um estrategista brasileiro de especificar a natureza do poder do Brasil no mundo (Araújo Castro, 1958).

Gerações sucessivas de estadistas estrangeiros que lidaram com o Brasil encontraram alguma dificuldade para digerir esse raciocínio. Quando o Presidente Richard Nixon e seu conselheiro de segurança nacional Henry Kissinger ofereceram ao Brasil um plano de engajamento diplomático na década de 1970, ouviram uma negativa do regime militar. O Brasil, disseram os militares, era certamente uma potência emergente; isto, esclareceram, não significava que o país fosse também uma potência regional disposta a coordenar-se com os Estados Unidos. Segundo a argumentação brasileira, os Estados Unidos deviam oferecer concessões especiais ao Brasil baseadas na noção de status especial, mas Washington não devia confundirse: esse reconhecimento devia basear-se nas qualidades inerentes da diplomacia brasileira, não em noções vagas sobre um suposto papel assertivo brasileiro na região (Spektor, 2007).

Naturalmente, isso criou alguns problemas para o Brasil. Se a obtenção de status especial nas relações internacionais sempre é uma operação crivada por dificuldades, a relutância de um país em assumir sua identidade de "potência regional" pode tornar o processo ainda mais difícil. Este aspecto do caso brasileiro ganha relevo particular nas relaçóes com os Estados Unidos, cuja grande estratégia global valoriza a existência de alianças com potências regionais dispostas e capazes de pagar alguns dos custos da manutenção da ordem em suas respectivas regiôes. Assim, não raro as expectativas americanas em relação ao papel regional Brasil chocam-se com as prioridades do próprio Brasil.

Mais de uma vez, houve vozes em Washington que buscaram aproximar-se ao Brasil nessas bases - vide Elihu Root com o Barão do Rio Branco no início do século XX, Nixon/Kissinger com os governos Médici e Geisel durante a década de 1970, e George W. Bush com o governo Lula na década de 2000. Em todas essas instâncias, o princípio básico de Washington era o de que o Brasil poderia conduzir um jogo regional capaz de reduzir a necessidade de compromisso americano na região. Nesses casos, contrariamente a um tipo de percepção que ainda goza de raízes profundas no Brasil, a abordagem americana para a América do Sul não é uma de controle estreito ou interesse inquestionável, mas a de relativa indiferença e aversão à exposição e ao custeio da ordem regional. Nesses casos os americanos surpreenderam-se ao descobrir que o lado brasileiro não respondia bem a modelos 
tradicionais de delegação de poder e autoridade, achando-os excessivamente custosos e fora de compasso com os interesses regionais do Brasil. A mensagem recorrente do Brasil é a de que o país "pode e deve contribuir na construção da ordem global [...], consciente de seu peso demográfico, territorial, econômico e cultural, e de ser uma grande democracia em processo de transformação social."' $\mathrm{O}$ que não aparece nesta lista é a noção de que, sendo o principal país do sub-continente, o Brasil teria responsabilidades especiais pela manutenção da estabilidade regional.

No entanto, conforme indicado acima, desde o fim da Guerra Fria o lugar da região têm ganhado proeminência no horizonte conceitual da política externa brasileira. Aqui há três ideias principais que coexistem. A primeira sustenta que a região importa porque é uma das principais fontes de instabilidade no ambiente externo. De fato, a região contém vários Estados relativamente frágeis, como Bolívia, Paraguai e Equador. O que lá acontece tem afetado interesses brasileiros de maneira direta - seja em relação ao investimento privado, ao crédito público ou às comunidades de cidadãos brasileiros vivendo nesses países.

Ao longo da década de 2000 a ideia do regionalismo como resposta aos problemas inerentes da região ganhou importância adicional porque sua trajetória ocorreu em paralelo a outros desenvolvimentos conceituais de grande consequência. Por um lado, a diplomacia brasileira contemporânea passou a considerar a democracia procedural como um requisito para a inserção bemsucedida da região sul-americana nas relações internacionais. Assim, um revés nas credenciais democráticas de qualquer país regional tem, para o Brasil, repercussōes estratégicas internacionais. Por outro lado, na concepção brasileira, a instabilidade regional é uma causa de potencial atenção norte-americana na região, fenômeno que o Brasil tem se empenhado em evitar. A situação é particularmente delicada para o Brasil, porque seus vizinhos dividem-se entre aqueles que almejam uma aproximação maior com os Estados Unidos e podem constituir porta de entrada para interesses americanos na América do Sul (Colômbia e Chile); e aqueles que, ao contestar a hegemonia americana, despertam a preocupação de Washington e, por força de sua oposição, terminam pondo a região em seu mapa de prioridades (Bolívia e Venezuela).

Desse ponto de vista, a região constituiria um "calcanhar de Aquiles" para o Brasil, cuja política regional almejaria menos a acumulação de poder do que a redução de riscos e a proteção contra os efeitos deletérios da instabilidade dentro de países vizinhos. Essa preocupação ajuda a explicar por que o Brasil parece estar abandonando sua enraizada relutância em institucionalizar as relações de segurança na região para produzir uma nova arquitetura - quiçá sob a égide do Conselho Sul-Americano de Defesa - que evite respostas ad hoc da comunidade regional ou respostas mais ou menos intervencionistas por parte dos Estados Unidos.

6 Discurso proferido pelo Embaixador Celso Amorim por ocasião da transmissão do cargo de Ministro de Estado das Relaçôes Exteriores - Brasília, Brasil, 1 de janeiro de 2003. 
A segunda ideia que marca este período prega que a região pode funcionar como um escudo contra alguns dos aspectos mais negativos do sistema capitalista global. O argumento é mais sofisticado quando se refere ao comércio: dessa perspectiva, os objetivos a longo prazo por detrás da política regional brasileira são de controlar a globalização e proteger a economia nacional de choques externos. Esta ideia não é nova e, ao menos em parte, suas origens remontam à década de 1960. O importante aqui é notar que a leitura brasileira do regionalismo após o fim da Guerra Fria continua enfatizando menos os objetivos comuns com a vizinhança do que a proteção da capacidade nacional de fazer frente aos desafios da globalização. Assim, no caso brasileiro, as mudanças na composição da sociedade internacional típicas dos anos 1990 e 2000 - e a expansão do regionalismo como forma legítima e desejável de gerenciar a ordem internacional - não se traduziram no abandono de posturas autonomistas, mas na adequação das mesmas com o objetivo de manter algum espaço de manobra nacional no mundo.

A terceira ideia recorrente caminha em direção diferente às anteriores. Ressalta que a regiáo pode ser uma importante fonte de acréscimo do módico poder que o Brasil goza nas relaçóes internacionais. Segundo essa visão, sendo a economia dominante da região, o Brasil pode utilizar o agrupamento regional para ajudar a moldar o ambiente regional, facilitar entendimentos, diluir conflitos e, dessa forma, alavancar o poder de barganha nacional em negociações com o mundo industrializado. É difícil encontrar referências explícitas a essa visão porque o teor dos discursos tende a destacar as fraquezas e fragilidades do país, não sua força relativa. Conforme enfatiza o chanceler Celso Amorim: "Até mesmo um país grande como o Brasil é um país pequeno num mundo como esse [...] nós não temos a capacidade de falarmos sozinhos [...] Eu acredito que o Brasil não tem uma existência plena sem a união [com a América do Sul]." A A lógica subjacente enxerga na região uma plataforma de lançamento ou trampolim, e vê o Brasil como um imã que exerce algum grau de atração natural no ambiente regional devido ao peso da economia nacional.

É fundamental notar que este tipo de raciocínio não é óbvio em círculos brasileiros. Ao contrário, durante gerações, os principais estrategistas acreditavam que o mecanismo de poder dominante na América do Sul era o equilíbrio de poder. Ou seja, diante de um Brasil assertivo, esperava-se que os vizinhos buscassem formar uma coalizão anti-hegemônica. De fato, esse medo explica boa parte da relutância brasileira de engajar a região até a década de 1970 (Spektor, 2002). A ideia de que o peso relativo do Brasil atrai (não afasta) os vizinhos é relativamente nova e revela uma interpretação sobre o funcionamento do poder nas relações regionais que aponta em direção oposta ao equilíbrio, valorizando a dinâmica

7 Discurso do Ministro das Relaçôes Exteriores, Embaixador Celso Amorim, por ocasião da cerimônia de abertura da III Conferência Ministerial da Comunidade das Democracias, Santiago, Chile, 24 de novembro de 2006. 
que a literatura especializada denomina de bandwagoning: a noção de que, diante do poder do Brasil, vizinhos menores tendem a segui-lo a reboque. É importante ressaltar que, ao menos na primeira década do século XXI, essas duas leituras opostas sobre a lógica do poder na América do Sul aparecem muitas vezes lado a lado no pensamento e escritos dos mesmos tomadores de decisão. E essa tensão não resolvida no coração do pensamento estratégico do país talvez ajude a explicar por que o Brasil nem aposta decididamente no projeto regionalista profundo nem abandona o projeto integrador.

Três proposiçóes, portanto, marcam o pensamento brasileiro a respeito do ambiente regional: o Brasil pode gozar de poder, prestígio e influência nas relações internacionais sem que isso implique assumir o papel de potência regional; a região pode funcionar como um escudo protetor da "autonomia" nacional na era da globalização; e a região pode funcionar como uma plataforma de lançamento para o acréscimo de poder, prestígio e influência nacional. Apontando em direções distintas, as três convivem de modo flutuante e pouco confortável, ajudando a explicar, ao menos em parte, as ambigüidades da atitude brasileira em relação à América do Sul.

\section{Vazios e silêncios}

As ideias que sustentam a recente movimentação brasileira em direção à região estão marcadas, portanto, por silêncios significativos. Esta seção busca apontá-los explicitamente.

Em primeiro lugar, a trajetória recente das políticas regionais do Brasil não parece refletir uma crença em que a pesada agenda de problemas regionais demande soluções necessariamente compartilhadas ou multilaterais. $\mathrm{O}$ ativismo regional do Brasil, ali onde existe, segue duas lógicas. Por um lado, a proteção contra ameaças e a preservação do espaço de manobra brasileiro (contra a instabilidade regional, a interferência americana ou os efeitos negativos da globalização). Para atingir este fim, o regionalismo é visto como útil porque produz densa camada de acordos, entendimentos e instituiçôes regionais que funcionam como uma rede capaz de conter, mitigar e dificultar a atuação dessas ameaças. Por outro lado, o ativismo regional seria uma ferramenta de acréscimo de poder e alavancagem dos interesses mais amplos do Brasil no mundo. Em ambos os casos a ênfase está na manutenção de uma região relativamente calma, com algum grau de cooperação econômica e institucionalização entre os países. Contudo, tendo em vista que esses desenvolvimentos são concebidos como instrumentais para maximizar a liberdade de ação do Brasil, sua estrutura deve ser flexível, relativamente fina e sempre dependente das decisões dos governos nacionais. Isto, claro, gera problemas pouco triviais: a camada institucional deve ser suficientemente densa para proteger os interesses nacionais, mas sua densidade não deve chegar ao ponto de embotar o poder brasileiro nem amarrar institucionalmente as escolhas de Brasília. 
Um segundo silêncio expressivo diz respeito ao fato de a política regional do país não ser apresentada em termos de governança regional ou mesmo do potencial valor agregado que a presença brasileira na região poderia ter sobre a ordem global mais ampla. Assim, para o chanceler Celso Amorim, a política de aproximação à região "é um objetivo a ser perseguido não apenas por causa da solidariedade regional, mas também em vista do nosso próprio progresso e bem-estar." Não há dúvida de que a solidariedade e o interesse nacional são fatores importantes nos cálculos brasileiros sobre a região. Do ponto de vista analítico, porém, a questão interessante, aqui e em outras declaraçôes de autoridades brasileiras desde o fim da Guerra Fria, é a relativa falta de referências ao papel preciso que o Brasil poderia vir a ocupar no gerenciamento de problemas regionais. Dessa maneira, apesar de as lideranças nacionais verem a "integração da América do Sul como uma necessidade, mas também como um projeto", os componentes desse projeto geralmente não são explicitados. ${ }^{9} \mathrm{O}$ argumento constante de que o Brasil está fundamentalmente comprometido em aumentar os graus de "cooperação regional" na América do Sul dão poucas pistas sobre o modelo preciso que se tem em mente.

O discurso proferido pelo presidente Lula em seminário intitulado "Brasil: ator global" ilustra o ponto: "A expressão 'ator global' pode produzir dois malentendidos. O primeiro seria a crença de que o Brasil, um país com problemas sociais e sem meios importantes de projetar seu poder militar internacionalmente, não pode aspirar ser um ator pleno globalmente [...]. O segundo engano é pensar que o Brasil, somente porque possui um vasto território, recursos naturais abundantes e uma população numerosa, terá automaticamente um papel relevante na esfera internacional. Felizmente, o Brasil está longe dessas duas perspectiva extremas". ${ }^{10}$ Trata-se de um argumento importante, mas o elemento mais evidentes é sua definição pela negativa: para o presidente, as amplas hipotecas internas do país não impedem o país de ser "ator pleno" nas relaçôes internacionais; enquanto as capacidades materiais relativamente vastas do país tampouco lhe asseguram posição de relevo óbvia. Se o Brasil está longe desses dois extremos, onde se encontra exatamente? O que move o Brasil na região além da busca de interesses pontuais? Um dos problemas de todo ator global é justamente o de reconciliar seus interesses nacionais com a provisão de algum tipo de bem público e com a resolução de alguns dos dilemas de ação coletiva que caracterizam as relações internacionais. O Brasil ainda não articulou uma resposta a esse dilema apesar de ser o principal país em sua região e de já contar com um acervo não trivial de políticas regionais - muitas das quais constituem bens públicos ou ajudam a resolver impasses de ação coletiva.

O terceiro silêncio importante diz respeito ao conteúdo normativo da política regional brasileira. Ao que tudo indica, o Brasil não vê a região como um centro

8 Celso Amorim, 1 de janeiro de 2003.

9 Celso Amorim, discurso no Curso de Diplomatas Sul-Americanos, Brasília, 25 de agosto de 2006.

10 Presidente Lula, discurso no seminário "Brasil: Ator Global”, Paris, 13 de julho de 2005. 
normativo distintivo na sociedade internacional. As iniciativas regionais do país não falam nem promovem um "estilo sul-americano" de participação nas relaçōes internacionais, como tenta fazê-lo a China com o "estilo asiático" ou o "estilo Ásia-Pacífico" (Acharya, 1997). A política regional brasileira também não ressalta uma cultura ou conjunto de valores exclusivistas, como ocorre com o projeto Bolivariano da Venezuela de Hugo Chávez (Hurrell, 2007). Nesse sentido, não parece haver, no Brasil, uma percepção de comunidade compartilhada ou de um ethos comum para dar base ao movimento regionalista. Isso talvez ajude a explicar por que a política externa brasileira - refletindo a opinião pública nacional - tem dificuldades em introduzir noções de justiça distributiva em suas relaçōes com a região. Quando se manifestam na prática, essas noçōes geralmente encontram expressão em gestos distributivos em questôes comerciais, de investimento e de migração. Entretanto, as medidas tendem a ser ad hoc e, apesar de infligir altos custos de imagem para a chancelaria, geralmente não satisfazem vizinhos menores, que gostariam de ver essas políticas institucionalizadas.

O quarto silêncio refere-se à opinião dos vizinhos do Brasil. De modo geral, e apesar de sua clara fraqueza relativa, os vizinhos não temem o Brasil nem estruturam seus sistemas de segurança em função de uma possível guinada hostil brasileira. Entretanto, embora eles não "percam o sono" por causa do Brasil, mantém vivo o anseio, a incerteza e a desconfiança diante das intençôes brasileiras. Diferentemente da China, cuja ascensão a levou a buscar uma política de resseguro ativo para seus vizinhos menores, o Brasil não acredita que os medos dos vizinhos sejam suficientemente intensos para merecer políticas dedicadas a diluí-los. Isto representa um problema, porque um dos componentes essenciais das dinâmicas de bandwagoning - pelas quais países relativamente fracos seguem o país mais forte a reboque - são compromissos do parceiro mais poderoso para reduzir as incertezas típicas da assimetria de poder de modo explícito e institucionalizado. É plausível esperar que, caso a ideia de bandwagoning ganhe raízes duradouras no pensamento diplomático brasileiro, os formuladores de política externa tenham de desenvolver iniciativas de resseguro desse tipo.

Finalmente, o quinto vazio recorrente no mercado de ideias sobre a regiáo diz respeito ao lugar dos Estados Unidos na estratégia regional brasileira. Em 2005, a Secretária de Estado Condoleezza Rice disse que o Brasil estava "emergindo como uma potência global [...] um grande [parceiro dos Estados Unidos] no futuro". Ela falou sobre o "papel global crescente do Brasil" e sobre a habilidade brasileira de ajudar a estabilizar e promover a afluência na região. O semanário inglês The Economist revelou a expectativa de muitos, em Washington, de que o Brasil pudesse desempenhar uma influência moderada para lidar com a instabilidade sul-americana. ${ }^{11}$ Segundo o argumento tácito nessas assertivas, o ordenamento nas

11 Ver Secretária Rice, comentários sobre a Embaixada dos Estados Unidos em Brasília, 26 de abril de 2005; Comentários por Secretária Rice e Ministro das Relações Exteriores, Celso Amorim, Itamaraty, Brasília, 26 de abril de 2005; e Secretária Rice, Comentários no museu Memorial Juscelino Kubitschek, Brasília, 27 de abril de 2005. Ver também The Economist, 30 de abril de 2005. 
Américas somente teria a ganhar se os dois maiores, mais ricos e mais poderosos países hemisféricos - Estados Unidos e Brasil - se engajassem em uma parceria mutuamente proveitosa. No início da década de 2000, forças-tarefa independentes em ambos os países avançaram argumentos nessa direção. ${ }^{12}$

No entanto, esses argumentos nunca terminaram por ganhar força no arcabouço conceitual brasileiro. A disjunção entre as expectativas americanas e brasileiras é enorme porque, nos cálculos de Brasília, o relativo distanciamento da grande potência hegemônica é benéfico. Uma política de aproximação sistemática para facilitar a governança regional, ao contrário, estaria cheia de ameaças e problemas. Na leitura brasileira, fazer negócios bilaterais em situação de tamanha assimetria teria efeitos deletérios para o parceiro mais fraco. As preocupações americanas na América do Sul - estejam elas ligadas ao tráfico de drogas, à convulsão política de alguns países, ou ao chavismo - causam considerável desassossego no Brasil. Como disse o ex-presidente Fernando Henrique Cardoso: "Quanto menos a gente estiver no radar dos Estados Unidos, melhor". ${ }^{13}$ Afinal, esta é a área do mundo onde os Estados Unidos são, de fato, o hegemon regional com poder esmagador.

Isso dito, é importante não confundir o comportamento brasileiro com uma mera tentativa de minar a influência americana na região. Brasília é consciente da necessidade imperiosa de não alienar Washington em temas regionais, mantendo os Estados Unidos engajados - inclusive como forma de prevenir reações americanas inesperadas. A trajetória da negociação de um Conselho Sul-Americano de Defesa em 2008 é ilustrativa. Do ponto de vista brasileiro, tratou-se de uma iniciativa voltada para o objetivo de reduzir as chances de intervenções americanas em temas e conflitos regionais, aumentar as instâncias de cooperação para a segurança, e assegurar que os interesses brasileiros não sejam atropelados. Mas a lógica da iniciativa sugere um sistema de múltiplas camadas de consultas superpostas onde os canais de comunicação com os Estados Unidos cumprem uma função crucial. Não é mera coincidência que, antes de levar a ideia aos países sul-americanos, o ministro da Defesa brasileiro fosse discutir o assunto em Washington. Assim, seria simplista caracterizar a atitude brasileira como uma estratégia para esconder-se da potência hegemônica. Os elementos apontados acima indicam que o Brasil tem tentado projetar uma visão relativamente sofisticada (embora ambígua) da região, e um conjunto nuançado de políticas regionais que, ao menos na opinião de seus formuladores, podem satisfazer os principais anseios brasileiros.

12 Council on Foreign Relations Independent Task Force Report: A Letter to the President and a Memorandum on US Policy Toward Brazil (2001) e Centro Brasileiro de Relaçōes Internacionais, Força Tarefa Independente: Relatório sobre os Estados Unidos da América (2002).

13 Folha de São Paulo, 4 de agosto de 2004. 


\section{Conclusão}

Durante a maior parte do século XX, sucessivos estadistas brasileiros consideraram a vizinhança como um lugar complexo e potencialmente hostil. O resultado foi uma orientação geral de política externa voltada para outros lugares do mundo. Essa atitude tradicional vem sendo transformada desde o fim da década de 1970 e chegou a seu ápice histórico nos anos 2000. Nesse período, em que pesem as vastas mudanças globais e regionais, o pensamento diplomático brasileiro manteve-se firmemente enraizado em concepções autonomistas.

Entretanto, há componentes de inovação nas leituras brasileiras da região que estão por trás do crescente ativismo do país na América do Sul. Este artigo indicou a existência de uma mudança ideacional significativa: a passagem de "América Latina" para "América do Sul"; o aparecimento de princípios regionalistas que incluem ideias inusitadas como a da "não-indiferença", que busca conciliar o apreço pela norma da soberania com as transformaçôes do ambiente normativo global; a busca parcial por institucionalizar aspectos da defesa e da segurança regionais. Ainda no leque das transformações na maneira brasileira de ler o sistema internacional está a ideia de que o regionalismo é um dos instrumentos mais eficientes para aumentar o espaço de manobra nacional em um mundo unipolar e em uma região na qual os Estados Unidos são potência inconteste.

Embora ainda estejam crivadas pela ambivalência e algum grau de contradição, essas ideias são consequentes. Elas revelam que o Brasil interpreta o sistema internacional de maneira diferente de outras potências regionais e de seus vizinhos sul-americanos mais influentes. Também revela que, em Brasília, o regionalismo é visto em termos instrumentais de cálculo de poder - um meio para obter determinados fins de política externa. Diferentemente do que ocorre em outros quadrantes, o regionalismo não revela uma transformação da identidade do país no mundo. Tomar consciência da natureza dessas ideias e acompanhar sua evolução no tempo é necessário para entender quais tipos de estratégias o país adota ou está em vias de adotar.

\section{Referências bibliográficas}

ACHARYA, Amitav. How Ideas Spread: Whose Norms Matter? Norm Localization and Institutional Change in Asian Regionalism. International Organization, 58 (Spring), 2004, p. 239-275.

ACHARYA, Amitav. Ideas, Identity and Institution-Building: from the 'ASEAN Way' to the 'Asia Pacific Way'. Pacific Review, 10 (3), 1997, p. 319-46.

Amorim, Celso. 2006. Discurso por ocasião da cerimônia de abertura da III Conferência Ministerial da Comunidade das Democracias em 24 de novembro, Santiago, Chile. Publicado em: [http://www.itamaraty.gov.br/sala-de-imprensa/discursos-artigos-entrevistas-e-outrascomunicacoes/embaixador-celso-luiz-nunes-amorim/762022303357-discurso-do-ministrodas-relacoes-exteriores] Disponibilidade: 28/5/2010. 
Amorim, Celso. 2003. Discurso por ocasião da transmissão do cargo de Ministro de Estado das Relações Exteriores em 1 de janeiro de 2003. Publicado em: [http://www.itamaraty.gov. $\mathrm{br} /$ sala-de-imprensa/discursos-artigos-entrevistas-e-outras-comunicacoes/embaixador-celsoluiz-nunes-amorim/Discurso-proferido-pelo-Embaixador-Celso-Amorim] Disponibilidade: $28 / 5 / 2010$.

ARAUJO CASTRO, J. O Poder Nacional: Limitações da Ordem Interna e Externa. Parcerias Estratégicas, 6 (Março), 2009. Seção Memória - Conferência na Escola Superior de Guerra (ESG), proferida em 1958.

ATKINS, G. Pope (Ed.). South America into the 1990s: Evolving International Relationships in a New Era. Boulder: Westview Press, 1990.

BURGES, Sean. Consensual Hegemony: Theorizing Brazilian Foreign Policy after the Cold War. International Relations, 22 (1), 2008, p. 65-84.

BURR, Robert N. By reason or force. Chile and the balancing of power in South America, 1830 1905. Berkeley: University of California Press, 1965.

BUZAN, Barry. People, States and Fear: and Agenda for International Security Studies in the post-Cold War Era. London: Harvester Wheatsheaf, 1991.

FAWCETT, Louise; HURRELL, Andrew (Eds.). Regionalism in World Politics: Regional Organization and International Order. Oxford: Oxford University Press, 1995.

FINNEMORE, Martha. The Purposes of Intervention: Changing Beliefs about the Use of Force. Ithaca: Cornell UP, 2003.

FOOT, Rosemary. Chinese Power and the Idea of a Responsible State. China Journal, 45, 2001, p. 1-19.

FOOT, Rosemary. Rights Beyond Borders: the Global Community and the Struggle over Human Rights in China. Oxford: Oxford University Press, 2000.

GOLDSTEIN, Judith. Ideas, Interests, and American Trade Policy. Ithaca: Cornell UP, 1993.

HIRST, Monica. Brasil e Estados Unidos: desencontros e afinidades (conclusão por Andrew Hurrell). Rio de Janeiro: Editora FGV, 2009.

HIRST, Monica; SOARES DE LIMA, M.R. Brazil as an Intermediate State and Regional Power. International Affairs, 82 (1), 2006, p. 21-40.

HOLSTI, KJ. The State, War and the State of War. New York: Cambridge University Press, 1996.

HURRELL, Andrew. On Global Order: Power, Values, and the Constitution of International Society. Oxford: Oxford University Press, 2007.

HURRELL, Andrew. The United States and Latin America. In: WOODS, N (Ed.). Explaining International Relations since 1945. Oxford: Oxford University Press, 1996, p. 163-164.

HURRELL, Andrew. Brazil as a Regional Great Power: a Study in Ambivalence. In: NEUMANN, Iver (Ed.). Regional Great Powers in International Politics. London: St Martin's Press, 1992.

KECK, Margaret; SIKKINK, Kathryn. Activists Beyond Borders: Advocacy Networks in International Politics. Ithaca: Cornell University Press, 1998.

RISSE-KAPPEN, Thomas. Ideas Do Not Flow Freely: Transnational Coalitions, Domestic Structures, and the End of the Cold War. International Organization, 48 (2), 1994, p. 185-214. 
ROSE, Gideon. Neoclassical Realism and Theories of Foreign Policy. World Politics, 51/1, 1998, p. 144-172.

SOUZA, Amaury de. A Agenda Internacional do Brasil Revisitada: percepçôes da comunidade brasileira de politica externa. Rio de Janeiro: Cebri, 2008.

SPEKTOR, Matias. Equivocal Engagement: Kissinger, Silveira, and the Politics of US Brazil Relations (1969-1983). Tese de Doutorado em Relações Internacionais. Universidade de Oxford. Oxford, 2007.

SPEKTOR, Matias. O Brasil e a Argentina entre a cordialidade oficial e o projeto de integração: a política externa do governo de Ernesto Geisel (1974-1979). Revista Brasileira de Política Internacional, v. 1., 2002, p. 117-145.

TANNENWALD, Nina; WOHLFORTH, William. Ideas and the End of the Cold War. Special Issue of the Journal of Cold War Studies, 7 (2), Spring, 2005.

TILLEMA, H. K. International Armed Conflict since 1945: a Bibliographic Handbook of Wars and Military Interventions. Boulder: Westview Press, 1991.

VARGAS, João Augusto. Persuadir e legitimar: a argumentação brasileira em favor da reforma do Conselho de Segurança. Cena Internacional, vol. 10, n. 2, 2008, p. 119-128.

Recebido em 15 de junho de 2009

Aprovado em 20 de outubro 2009

\section{Resumo}

Este artigo estuda a transformação progressiva das leituras brasileiras sobre o ambiente regional durante as décadas de 1990 e 2000. Inicialmente, o ensaio caracteriza o padrão brasileiro de ativismo regional à luz das principais iniciativas adotadas pelo país e dos métodos utilizados para lidar com os obstáculos e ambiguidades inerentes à sua política regional. Em seguida, apresenta o leque de novos conceitos estratégicos que vêm informando o comportamento brasileiro na região. Por fim, o artigo aponta alguns dos silêncios e contradições mais recorrentes desse ideário emergente.

\section{Abstract}

This piece studies change in Brazil's readings of its regional environment since the 1990s. It begins by characterizing Brazil's latest pattern of regional activism, with an emphasis to the obstacles and ambiguities that inhere. It then presents the range of new strategic concepts that have informed Brazilian behavior in South America. The conclusion highlights the silences that recur.

Palavras-chave: política externa; América do Sul; Fernando Henrique Cardoso; Luiz Inácio Lula da Silva.

Key-words: foreign policy; South America; Fernando Henrique Cardoso; Luiz Inácio Lula da Silva. 